\title{
The hypertensive effect of sorafenib is abolished by sildenafil
}

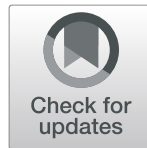

Hubert Dabiré ${ }^{1}$ Fatou Dramé ${ }^{1}$, Nelly Cita $^{1}$ and Bijan Ghaleh ${ }^{1,2^{*}}$

\begin{abstract}
Background: Contrasting to the well documented tyrosine kinase inhibitor (TKI)-induced hypertension, little is known on their intrinsic vasomotor effects. We investigated the vasomotor effects of sorafenib, a widely used multikinase inhibitor in the treatment of hepatocellular and renal cell carcinoma and tested the hypothesis that sildenafil, a phosphodiesterase-5 (PDE-5) inhibitor, could represent a pharmacological strategy for the treatment of TKl-induced hypertension.

Methods: Concentration-response curves of sorafenib were constructed in endothelium-intact or denuded precontracted rat aorta, in the presence or absence of several inhibitors. Acute intravenous effects of sorafenib on arterial blood pressure were also investigated in anaesthetized rats. Finally, rats were chronically treated with sorafenib during 4 weeks in the presence and absence of sildenafil.

Results: In endothelium intact aortic ring, sorafenib induced a potent concentration-dependent relaxation of precontracted rat aorta. Removal of the endothelium shifted the concentration-response curve of sorafenib to the right and significantly reduced its maximal effects, demonstrating that sorafenib-induced vasorelaxation is endothelium-dependent and endothelium-independent. Inhibition of the different pathways implicated in the endothelium-dependent and independent vasorelaxation revealed that the endothelium-dependent effects of sorafenib result mainly from the activation of prostaglandin and the nitric oxide (NO) pathways. The endotheliumindependent vasodilatory effects of sorafenib may result mainly from the activation of Na/K-ATPase and soluble guanylate cyclase. These vasodilatory effects observed in vitro were confirmed by the decrease in arterial blood pressure observed during acute administrations of sorafenib in anesthetized rats. Finally, and most importantly, we report here for the first time that chronic administration of sorafenib in rats induced an increase in SBP that was abolished by sildenafil.

Conclusion: The multikinase inhibitor sorafenib induced in vitro vasorelaxation of large conductance artery, primary by activating soluble guanylate cyclase. Its chronic administration led to arterial blood hypertension that was counteracted by a PDE-5 inhibitor, sildenafil. Our results suggest that targeting the cGMP pathway including NO signalling might be an interesting pharmacological strategy for the treatment of TKl-induced hypertension.
\end{abstract}

Keywords: Sorafenib, Tyrosine kinase inhibitor, Vasorelaxation, Phosphodiesterase-5 (PDE-5) inhibitor, Arterial blood pressure

\footnotetext{
* Correspondence: bijan.ghaleh@inserm.fr

'U955 - IMRB, Inserm, UPEC, École Nationale Vétérinaire d'Alfort, Créteil,

France

${ }^{2}$ INSERM U955 Équipe 03, Faculté de Médecine, 8 rue du Général Sarrail,

94000 Créteil, France
}

C C The Author(s). 2020 Open Access This article is licensed under a Creative Commons Attribution 4.0 International License, which permits use, sharing, adaptation, distribution and reproduction in any medium or format, as long as you give appropriate credit to the original author(s) and the source, provide a link to the Creative Commons licence, and indicate if changes were made. The images or other third party material in this article are included in the article's Creative Commons licence, unless indicated otherwise in a credit line to the material. If material is not included in the article's Creative Commons licence and your intended use is not permitted by statutory regulation or exceeds the permitted use, you will need to obtain permission directly from the copyright holder. To view a copy of this licence, visit http://creativecommons.org/licenses/by/4.0/ The Creative Commons Public Domain Dedication waiver (http://creativecommons.org/publicdomain/zero/1.0/) applies to the data made available in this article, unless otherwise stated in a credit line to the data. 


\section{Background}

Tyrosine kinase inhibitors (TKIs) that inhibit growth factors are widely used as targeted therapy for cancers [1-4]. One of their major current side effects is arterial hypertension [5-9]. This increase in blood pressure is considered as a landmark of their anticancer efficacy [5, 9-11]. Different mechanisms have been evoked such as direct inhibition of nitric oxide (NO) production, increased endothelin-1 release, NO deficiency-mediated increased proliferation of vascular medial cells, rarefaction of small arteries and arterioles or increased arterial stiffness [5, 9, 12-15]. Regarding the clinical management of this hypertension, current agents available for the treatment of essential hypertension are the same used for the treatment of TKIs-induced hypertension $[6,9,16,17]$.

This hypertensive effect of TKIs has also been observed in rodent and large animal models [18-23] but in vitro investigations on vessel rings are not always consistent with these observations. Imatinib, nilotinib and sorafenib induced concentration-dependent relaxation of rat pulmonary artery [24] and sunitinib blunted endothelin-1-induced vasoconstriction, reduced phenylephrine-induced maximal vasoconstriction and facilitated acetylcholine (Ach) -induced vasodilation of rat renal resistance arteries [22], showing a vasodilatory property of sunitinib on renal resistance arteries. This suggests that the in vivo effects of TKIs might not be the consequences of direct vasomotor properties. However, sunitinib produced vasoconstriction selectively in the systemic vascular bed without affecting pulmonary or coronary circulations in swine [20]. The reasons for these discrepancies remain unknown.

Accordingly, we decided to decipher the vasomotor properties of sorafenib which is widely used for the treatment of hepatocellular and renal cell carcinoma $[1,25,26]$. Sorafenib is a multikinase inhibitor, acting preferentially on vascular endothelial growth factor receptor (VEGFR), platelet derived growth factor receptor (PDGFR) and c-RAF (not a tyrosine kinase receptor). Our second goal was to investigate the in vivo effects of acute and chronic administration of sorafenib in rats. As our in vitro results showed major intervention of the cGMP-pathway in the vasomotor effects of sorafenib, we next hypothesized that phosphodiesterase-5 (PDE-5) inhibition with sildenafil [27-29] might represent an interesting strategy to counteract sorafenib-induced increase in arterial blood pressure. PDE-5 is cGMP selective and is expressed in numerous organs, e.g. smooth muscle, heart and kidney $[30,31]$. By preventing the degradation of cGMP to 5'GMP, inhibition of PDE-5 increases NO availability leading to potentiation of the NO-dependent vasodilatory effects.

\section{Methods \\ Animals}

Twelve-week old male Wistar rats (Janvier Labs, Le Genest-St-Isle, France) were maintained under $12 \mathrm{~h}$ light-dark cycle with free access to food and water. They were allowed a week period of acclimation in our laboratory animal facilities. All the experiments were carried out in accordance with current institutional guidelines for the care and use of experimental animals. They were approved by our local animal ethical committee [ComEth AFSSAENVA-UPEC approval \#12/09/17-3].

\section{Aortic rings preparation}

In vitro experiments were performed in isolated aortic rings as previously described [32-34]. Under pentobarbital anaesthesia $(60 \mathrm{mg} / \mathrm{kg}$ ip), the thoracic aorta was carefully excised and placed in cold Krebs solution containing (mM): $118.3 \mathrm{NaCl}, 4.7 \mathrm{KCl}, 2.5 \mathrm{CaCl}_{2}, 1.2$ $\mathrm{MgSO}_{4}, 1.2 \mathrm{KH}_{2} \mathrm{PO}_{4}, 25 \mathrm{NaHCO}_{3}, 0.016$ EDTA and 11.1 glucose. The aorta was cleaned of excess connective tissue and fat and cut into rings of approximately 3-4 $\mathrm{mm}$ in length. Special care was taken to avoid damaging the luminal surface of the endothelium. In experiments on endothelium-denuded rings, the endothelium was removed by gently rubbing the intimal surface with the tip of small forceps. Aortic rings were suspended in $10 \mathrm{ml}$ organ baths filled with Krebs solution continuously aerated with a mixture of $5 \% \mathrm{CO}_{2}, 95 \% \mathrm{O}_{2}, \mathrm{pH} 7.4$, at $37.4{ }^{\circ} \mathrm{C}$. One end of the aortic ring was connected to a tissue holder and the other to an isometric force transducer (EMKABath4, EMKA Technologies, Paris, France). Rings were progressively stretched to a resting tension of $2 \mathrm{~g}$ during $120 \mathrm{~min}$. During this equilibration period, the rings were washed every $20 \mathrm{~min}$. Then, a first relaxation to acetylcholine (Ach, $10^{-4} \mathrm{M}$ ) was implemented to check the integrity or the absence of the endothelium in rings precontracted with noradrenaline (NA, 3.10 $\mathrm{M})$. Rings were equilibrated again to baseline tension during $90 \mathrm{~min}$ by rinsing with Krebs solution.

\section{In vitro effects of sorafenib and sildenafil}

We examined the concentration-response curves of sorafenib $\left(10^{-10}-10^{-4} \mathrm{M}\right)$ in a first series of experiments. We also compared them to those of Ach $\left(10^{-10}-10^{-4} \mathrm{M}\right)$ and sodium nitroprusside (SNP, $10^{-10}-10^{-4} \mathrm{M}$ ) in endothelium-intact and endothelium-denuded aortic rings. For this purpose, the rings were incubated during 20 min with the solvent of each agent (dimethyl sulfoxide, DMSO, $90 \mu \mathrm{l}$ for sorafenib or distilled water, $90 \mu \mathrm{l}$ for Ach and SNP). Then after, cumulative concentration-response curves to sorafenib, Ach and SNP were constructed after precontraction with NA $\left(3.10^{-6} \mathrm{M}\right)$. Each concentration of the drugs was added at the maximal effect of the precedent concentration. Each ring was subjected 
to one concentration-response curve. The concentrationresponse curves were continuously recorded on a personal computer by means of IOX software v 2.9.4.35 (EMKA Technologies, Paris, France) for further analysis (Datanalyst software v 2.6.1.13, EMKA Technologies, Paris, France). In addition, the effects of sildenafil $\left(10^{-10}-10^{-4}\right.$ $\mathrm{M})$ on intact rat aortic rings were investigated in similar conditions and compared to those of Ach and SNP.

In a second series of experiments, the mechanisms of the vasorelaxation induced by sorafenib were investigated in endothelium-intact and endothelium-denuded aortic rings. The rings were incubated during $20 \mathrm{~min}$ with different inhibitors (Table 1 ) or their combinations. Then after, cumulative concentration-response curves to sorafenib $\left(10^{-10}-10^{-4} \mathrm{M}\right)$ were constructed as described above. Each ring was subjected to one inhibitor and one concentration-response curve.

The quantification of the results was performed by calculating the maximal effect $\left(\mathrm{E}_{\max }\right)$, the concentration inducing $50 \%$ of $\mathrm{E}_{\max }\left(\mathrm{EC}_{50}\right)$ and $\mathrm{pEC}_{50}\left(-\log \left(\mathrm{EC}_{50}\right)\right)$.

\section{Acute effects of sorafenib on blood pressure in anaesthetized rats}

Arterial blood pressure (BP) was recorded as previously described [45]. Briefly, under anaesthesia with pentobarbital sodium $(60 \mathrm{mg} / \mathrm{kg}$ ip), a polyethylene catheter [a PE-10 (0.28 mm ID, 0.61 mm OD; Clay Adams, Parsippany, NJ) fused to a PE-50 (0.58 mm ID, $0.96 \mathrm{~mm}$ OD; Guerbet, Louvres, France)] filled with heparinized 0.9\% $\mathrm{NaCl}(50 \mathrm{U} / \mathrm{ml})$ was inserted into the common carotid artery and connected to a signal processor (MP35, Biopac Systems Inc., CA, USA) via a pressure transducer (BP-T, EMKA Technologies, Paris, France). Blood pressure signals were recorded online at a sampling rate of 250 points/s (BSL Pro 3.7, Biopac Systems Inc., CA, USA). Another catheter was introduced into the femoral vein for drugs administration. After $30 \mathrm{~min}$ of stabilisation, increasing doses of sorafenib were administered intravenously as a bolus (0.1, 0.3 and $1 \mathrm{mg} / \mathrm{kg})$. Each dose was given after blood pressure had returned to baseline value and each rat was subjected to one doseresponse curve.

\section{Chronic effects of sorafenib on blood pressure in conscious rats}

Non-invasive tail-cuff measurement of systolic blood pressure (SBP) was used to follow the changes in blood pressure during the four-weeks treatment protocol [46]. The rats were kept in a rodent restrainer in a quiet room. The tail was placed on a piezoelectric sensor connected to a Powerlab 2/20 (ADInstruments Pty Ltd., Australia) and, around an inflator, connected to a NIBP Controller (ADInstruments Pty Ltd., Australia). The NIBP Controller was connected to the Powerlab 2/20 which itself was connected to a personal computer allowing recording of pressure waveforms by mean of Chart $^{\circ}$ software (ADInstruments Pty Ltd., Australia).

Rats were trained once a day during 5 days before basal SBP recording. They were then randomly assigned to 5 groups: a control, untreated group (CTRL), a DMSO-treated group (DMSO, $1 \mathrm{ml} / \mathrm{kg} / \mathrm{d}$ ), a sorafenibtreated group (SORA, $30 \mathrm{mg} / \mathrm{kg} / \mathrm{d}$ ), a sildenafil-treated group (SILD, $3 \mathrm{mg} / \mathrm{kg} / \mathrm{d}$ ) and a group treated by sorafenib plus sildenafil (SOSI, $30 \mathrm{mg} / \mathrm{kg} / \mathrm{d}$ plus $3 \mathrm{mg} / \mathrm{kg} / \mathrm{d}$, respectively). SBP was recorded in the morning, every day during the 5 first days of the treatment and every week then after. Drugs were given by gavage. At the end of the 4-weeks treatments, the rats were anesthetized, and aorta and end organs were harvested for in vitro investigations.

\section{Drugs}

Acetylcholine (Ach), sodium nitroprusside (SNP), LNAME, Ouabain and noradrenaline (NA) (Sigma Aldrich, St Quentin Fallavier, France) were dissolved in distilled water. Indomethacin and U73122 (Sigma Aldrich, St Quentin Fallavier, France), sorafenib, ODQ, rofecoxib, sildenafil and manoalide (CliniSciences, Nanterre, France) were dissolved in DMSO. The selectivity and the doses are indicated in Table 1.

Table 1 Inhibitors of the different pathways implicated in vasorelaxation

\begin{tabular}{|c|c|c|c|}
\hline Drugs & Selectivity & Concentration (M) & References \\
\hline U73122 & Phospholipase C & $10^{-5}$ & {$[35]$} \\
\hline Manoalide & Phospholipase $\mathrm{A}_{2}$ & $3.10^{-7}$ & [36] \\
\hline L-NAME & Nitric oxide (NO) synthase & $3.10^{-5}$ & [37] \\
\hline Indomethacin (INDO) & Cyclo-oxygenase (COX) & $3.10^{-5}$ & {$[38,39]$} \\
\hline Rofecoxib & Prostacyclin $\left(\mathrm{PGI}_{2}\right)$ synthase & $3.10^{-7}$ & {$[38-40]$} \\
\hline ODQ & Soluble guanylyl cyclase (sGC) & $10^{-5}$ & {$[41-43]$} \\
\hline Ouabain & $\mathrm{Na} / \mathrm{K}$-ATPase & $10^{-4}$ & {$[44]$} \\
\hline
\end{tabular}

U73122, 1-[6-\{[17ß-3-methoxyestra-1,2,3(10)-trien-17-yl]amino\}hexyl]-1H-pyrrole-2,5-dione; L-NAME, $\mathrm{N}^{\omega}$-Nitro-L-arginine methyl ester; ODQ, 1H -[1, 2, 4] Oxadiazolo [4,3-a]quinoxalin-1-one 


\section{Statistical analysis}

Values are means \pm SEM of the number of rats. Statistical analysis was performed with StatView software (v5, Abacus Concepts Inc.). ANOVA for repeated measures and one factor ANOVA followed by Fisher Protected Least significance were used to compare the effects of drugs. Differences were considered significant at $P<$ 0.05 .

\section{Results}

\section{Vasomotor effects of sorafenib}

In endothelium-intact aortic rings, sorafenib exhibited concentration-dependent vasorelaxation similar to the effects of Ach and SNP (Fig. 1a). Removal of the endothelium almost abolished the vasorelaxation induced by Ach $\left(\mathrm{E}_{\max }=86 \pm 4\right.$ vs $\left.22 \pm 7 ; P<0.001\right)$ and did not change that of SNP $\left(E_{\max }=100 \pm 1\right.$ vs $\left.104 \pm 2\right)$, confirming the absence of functional endothelium and preserved vascular smooth muscle function (Fig. 1c and d). Endothelium removal shifted the concentration-response curve of sorafenib to the right and reduced its $\mathrm{E}_{\max }$ from $99 \pm 1$ to $65 \pm 4 \%$ (Fig. 1b). These experiments revealed that sorafenib induces vasorelaxation through both endothelium-dependent and -independent mechanisms.

Vasorelaxation may result from direct effect on vascular smooth muscles or the release of a multiple endothelium-derived relaxing factors $[47,48]$ particularly $\mathrm{NO}$ and prostacyclin $\left(\mathrm{PGI}_{2}\right)$. In endothelium intact aortic rings, inhibition of phospholipase C (PLC) by U73122 $\left(10^{-5} \mathrm{M}\right.$; Fig. 2a) or NO synthase by L-NAME $\left(3.10^{-5}\right.$ M; Fig. 2b) shifted the concentration-response curves of sorafenib to the right and significantly reduced its maximal effects $\left(E_{\max }=67 \pm 7 \%\right.$ and $64 \pm 9 \%$ vs $\left.99 \pm 1 \%\right)$. Inhibition of soluble guanylyl cyclase (sGC) by ODQ $\left(10^{-5} \mathrm{M}\right.$; Fig. 2c) in the presence or the absence of the endothelium, produced similar effects.

Regarding the $\mathrm{PGI}_{2}$ pathway, inhibition of phospholipase $\mathrm{A}_{2}\left(\mathrm{PLA}_{2}\right)$ by manoalide $\left(3.10^{-7} \mathrm{M}\right.$; Fig. $\left.2 \mathrm{~d}\right)$, COX by indomethacin (INDO, $3.10^{-5} \mathrm{M}$; Fig. 2e) or $\mathrm{PGI}_{2}$ synthase by rofecoxib $\left(3 \cdot 10^{-7} \mathrm{M}\right.$; Fig. 2f) shifted the concentration-response curve of sorafenib to the right and significantly reduced its maximal effects in endothelium intact aortic rings $\left(\mathrm{E}_{\max }=43 \pm 3 \%, 49 \pm 4 \%\right.$ and $58 \pm 6 \%$ vs $99 \pm 1 \%$, respectively).
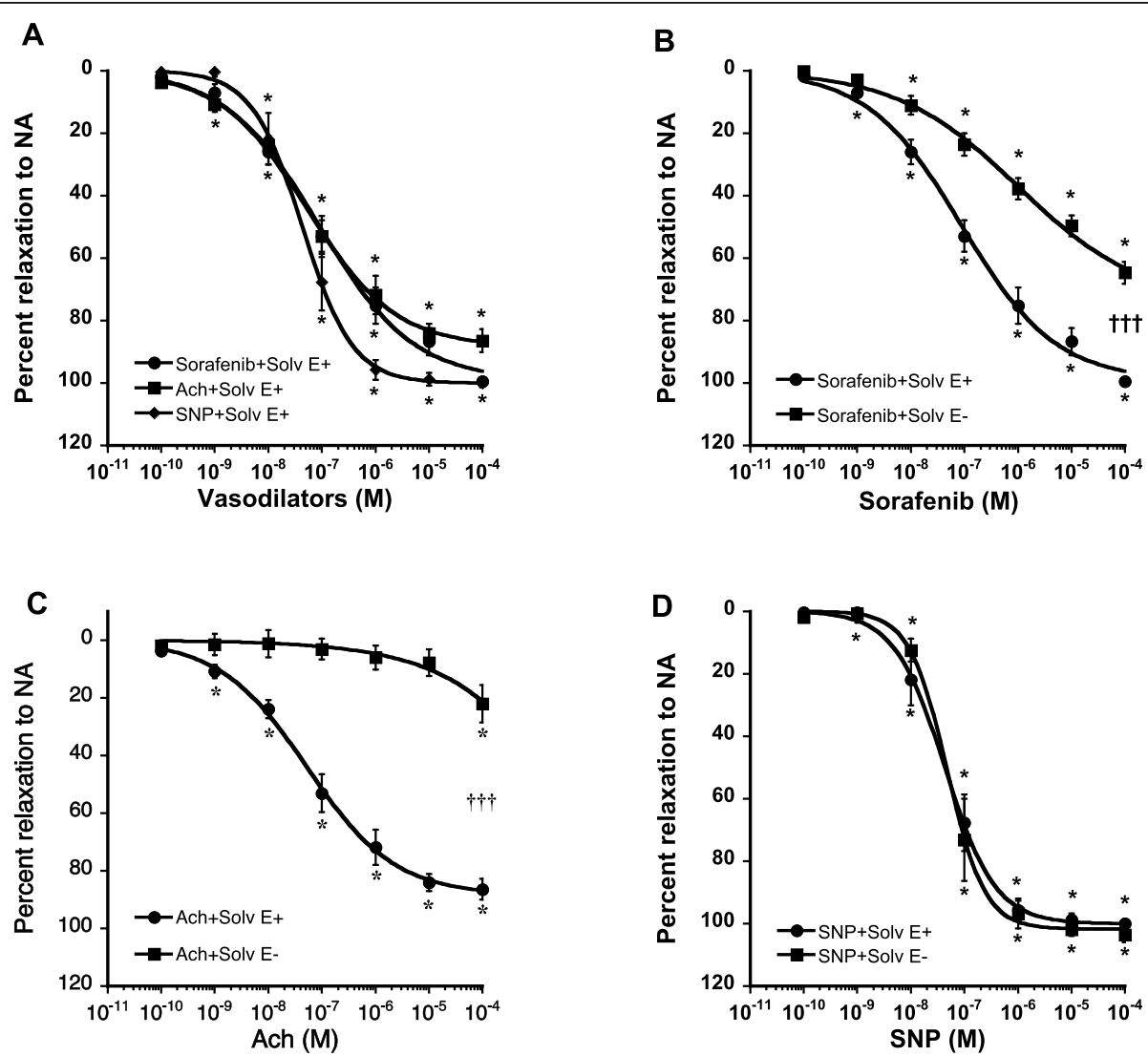

Fig. 1 Comparative concentration-response curves (a) of sorafenib (full circles), acetylcholine (Ach, full squares), and sodium nitroprusside (SNP, full diamonds) in endothelium intact rat aortic rings precontracted by NA $\left(3.10^{-6} \mathrm{M}\right)$. Concentration-response curves of sorafenib (b), Ach (c) and SNP (d) in endothelium intact (full circles) and denuded (full squares) rat aortic rings precontracted by NA $\left(3.10^{-6} \mathrm{M}\right)$. Each point is the mean \pm SEM of $6-15$ rats. * $P<0.001$ vs $10^{-10} \mathrm{M} ;$ +十† $P<0.001$ vs endothelium intact ring. ANOVA for repeated measures 


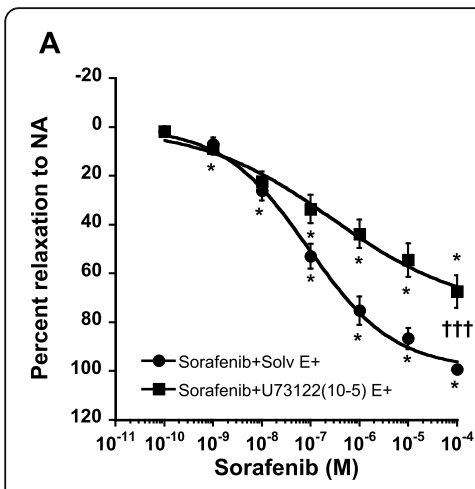

D

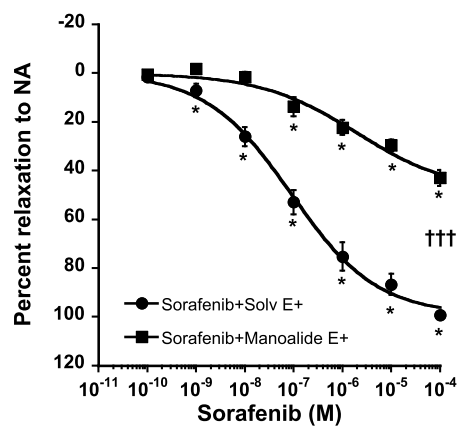

B

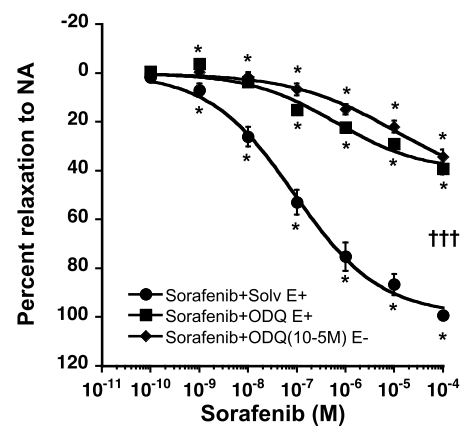

E

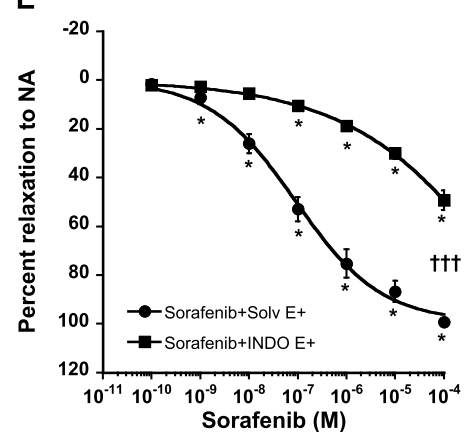

C

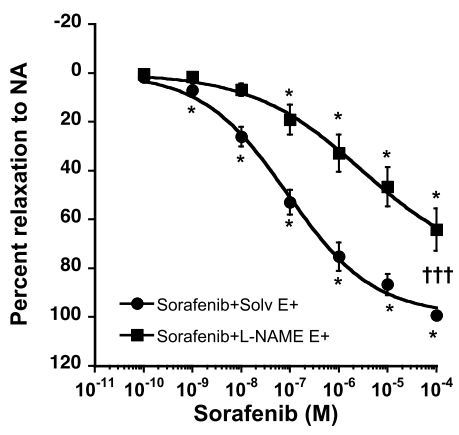

$\mathbf{F}$

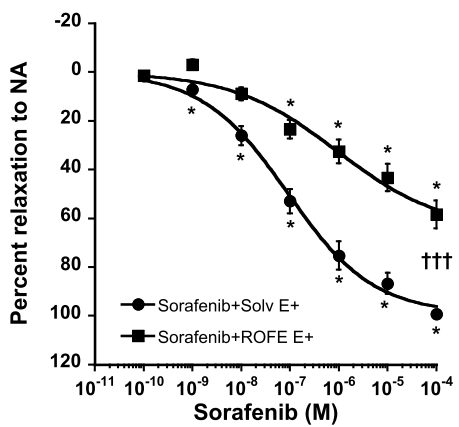

Fig. 2 Concentration response curves of sorafenib in endothelium intact rat aortic rings, in the presence of solvent (Solv, full circles) or different inhibitors (full squares): U73122 (a), L-NAME (b), ODQ (c; full diamonds, endothelium denuded), manoalide (d), indomethacin (INDO, e) and rofecoxib (ROFE, $\mathbf{f}$ ). Each point is the mean \pm SEM of 5-15 rats. ${ }^{*} P<0.001$ vs $10^{-10} \mathrm{M}$; $+\dagger+P<0.001$ vs Solvent. ANOVA for repeated measures

In endothelium intact rings, inhibition of $\mathrm{Na} / \mathrm{K}$-ATPase by ouabain $\left(\mathrm{OUA}, 10^{-4} \mathrm{M}\right)$ significantly reduced sorafenibinduced vasorelaxation and this effect was not altered by endothelium removal (Fig. 3a), $\mathrm{E}_{\max }$ values being similar $(47 \pm 4 \%$ vs $54 \pm 5 \%)$. In addition, endothelium removal did not alter the effects of combined inhibition of soluble guanylyl cyclase by ODQ and Na/K-ATPase (Fig. 3b).

\section{Vasomotor effects of sildenafil}

In endothelium-intact aortic rings, sildenafil exhibited concentration-dependent vasorelaxation similar to the effects of Ach and SNP (Fig. 4) with comparable maximal effect $(94 \pm 1 \%$ vs $86 \pm 4 \%$ and $100 \pm 1 \%$ for Ach and SNP, respectively).

\section{In vivo effects of acute administration of sorafenib in normotensive rats}

The effects of acute administration of sorafenib were investigated in normotensive anesthetized rats. Intravenous administration of the solvent (DMSO) did not change arterial blood pressure. In contrast, intravenous bolus administration of sorafenib $(0.1,0.3$ and $3 \mathrm{mg} / \mathrm{kg}$ ) induced a dose-dependent decrease in arterial blood pressure (Figs. 5a and b). This effect was short-lasting and arterial blood pressure rapidly returned to baseline values as illustrated in Fig. 5a.

In vivo effects of chronic sorafenib administration and its combination with sildenafil

Animals received chronic treatments (DMSO, SORA, SILD, SOSI) according to the protocol illustrated in Fig. 5c. No difference in SBP was observed among the 5 groups of rats before starting treatments $(121 \pm 4 \mathrm{mmHg}, 119 \pm 6 \mathrm{mmHg}$, $123 \pm 4 \mathrm{mmHg}, 121 \pm 3 \mathrm{mmHg}$ and $126 \pm 6 \mathrm{mmHg}$ in control, DMSO, SORA, SILD and SOSI groups, respectively). As illustrated in Fig. 5d, after an initial increase in SBP at the beginning of the protocol, SBP remained stable throughout the protocol in control animals. DMSO-treated animals showed similar SBP values than controls. In contrast, chronic administration of sorafenib rapidly induced a significant and stable increase in SBP. Interestingly, sildenafil did not significantly change SBP compared to control and DMSO groups but abolished the hypertensive effect of sorafenib with normalised values of SBP (Fig. 5d).

Chronic oral administration of sorafenib altered endothelium-dependent vasodilatory properties of sorafenib. We observed significantly reduced vasorelaxation when sorafenib was added to the aortic rings as compared to aortic rings obtained from vehicle treated animals $\left(E_{\max }=39 \pm\right.$ 


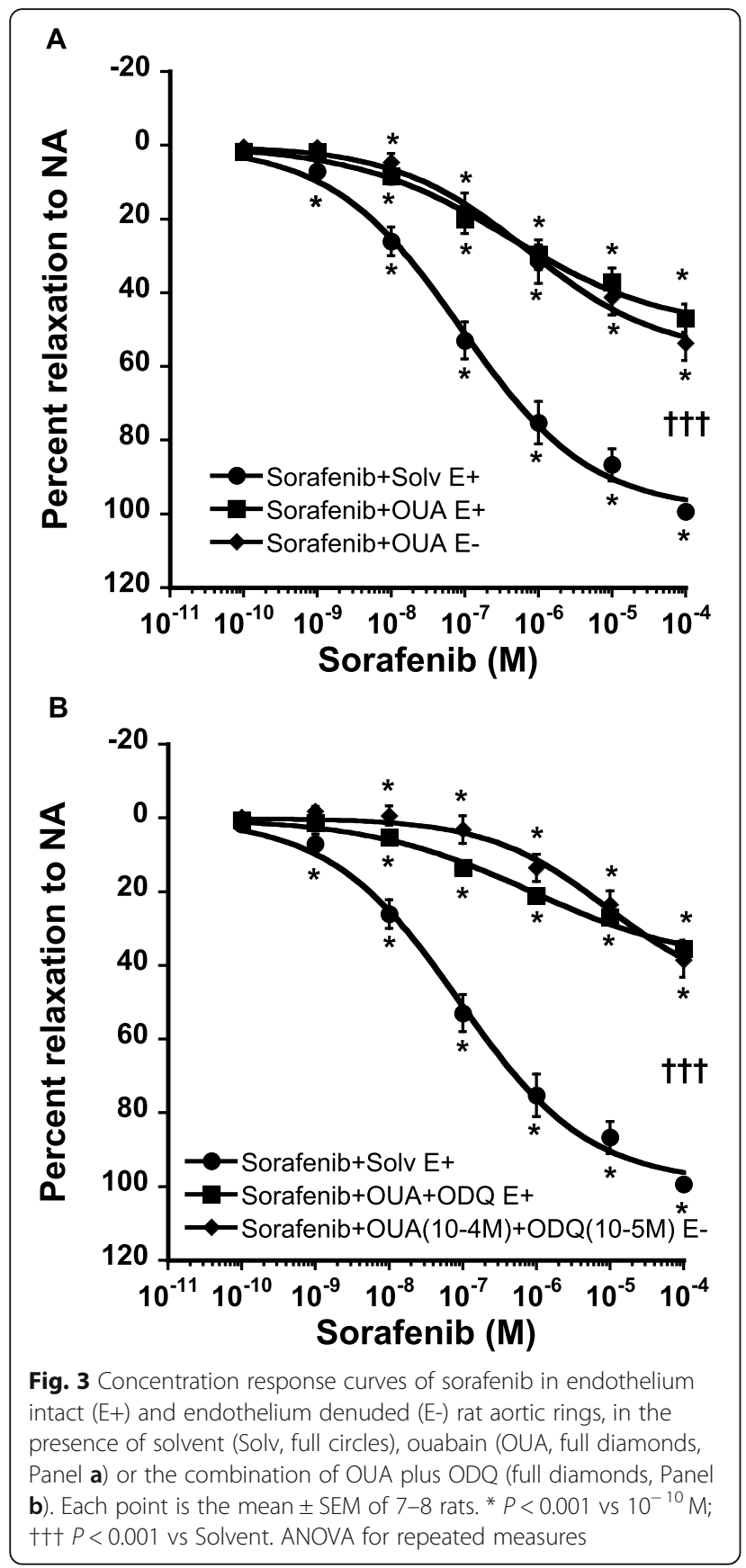

$10 \%$ vs $73 \pm 4 \% ; P<0.001)$ and more importantly, endothelium removal did not alter this response (Fig. 6).

\section{Discussion}

Notwithstanding the well documented tyrosine kinase inhibitor (TKI)-induced hypertension, little is known surprisingly on their intrinsic vasomotor effects. We investigated the vasomotor effects of sorafenib, a widely used multikinase inhibitor in the treatment of cancers and tested the hypothesis that sildenafil, a phosphodiesterase- 5 inhibitor, could represent a pharmacological strategy for the treatment of TKI-induced hypertension. In endothelium intact aortic ring, sorafenib induced a potent concentrationdependent relaxation of precontracted rat aorta. Removal of the endothelium shifted the concentration-response curve of sorafenib to the right and significantly reduced its maximal effects, demonstrating that sorafenib-induced vasorelaxation involves a dual mechanism, i.e., endothelium dependent and endothelium independent vasorelaxation. To determine the pharmacological mechanisms implicated in the sorafenib-induced vasorelaxation, we investigated the effects of several inhibitors. The results obtained revealed that the endothelium dependent effects of sorafenib result mainly from the activation of prostaglandin and the nitric oxide pathways. The endothelium independent vasodilatory effects of sorafenib may result mainly from the activation of $\mathrm{Na} / \mathrm{K}$-ATPase and soluble guanylate cyclase. These vasodilatory effects observed in vitro were confirmed by the decreases in arterial blood pressure observed during acute administrations of sorafenib in anesthetized rats. Finally, and most importantly, we report here for the first time that sildenafil abolished the increase in systolic blood pressure induced by chronic administration of sorafenib in rats.

Hypertension is one of the most frequently reported adverse effects associated with angiogenesis inhibitors, including sorafenib. Sorafenib-induced hypertension can occur in patients as early as within the first day from initiating therapy and is easily detectable after 1 week of treatment [49-52]. Similar results have been reported with sorafenib and sunitinib given by gavage in Wistar rats and Sprague-Dawley rats, regardless of whether

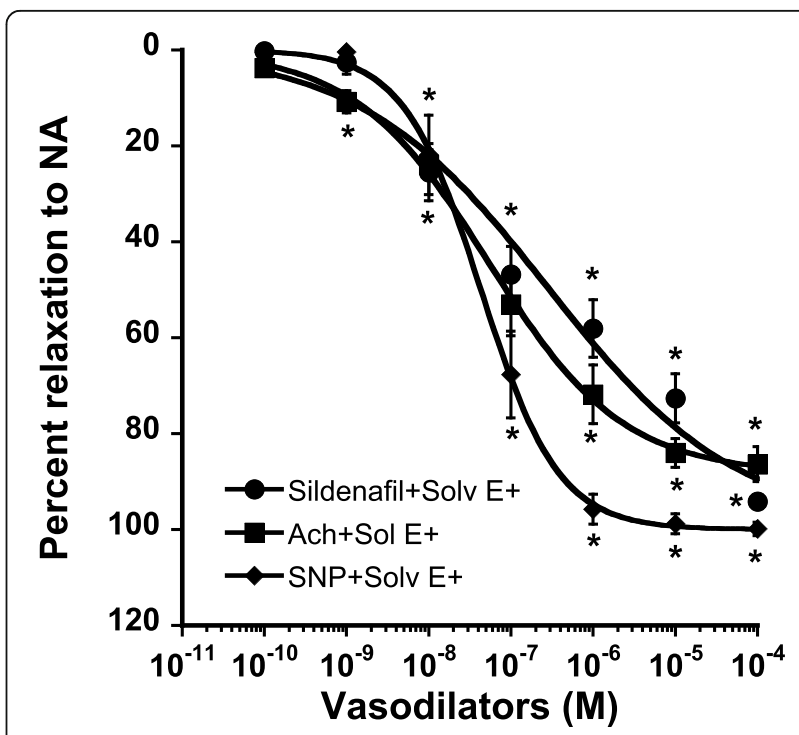

Fig. 4 Comparative concentration-response curves of sildenafil (full circles), acetylcholine (Ach, full squares), and sodium nitroprusside (SNP, full diamonds) in endothelium intact rat aortic rings precontracted by NA $\left(3.10^{-6} \mathrm{M}\right)$. Each point is the mean \pm SEM of $7-$ 9 rats. ${ }^{*} P<0.001$ vs $10^{-10} \mathrm{M}$. ANOVA for repeated measures 


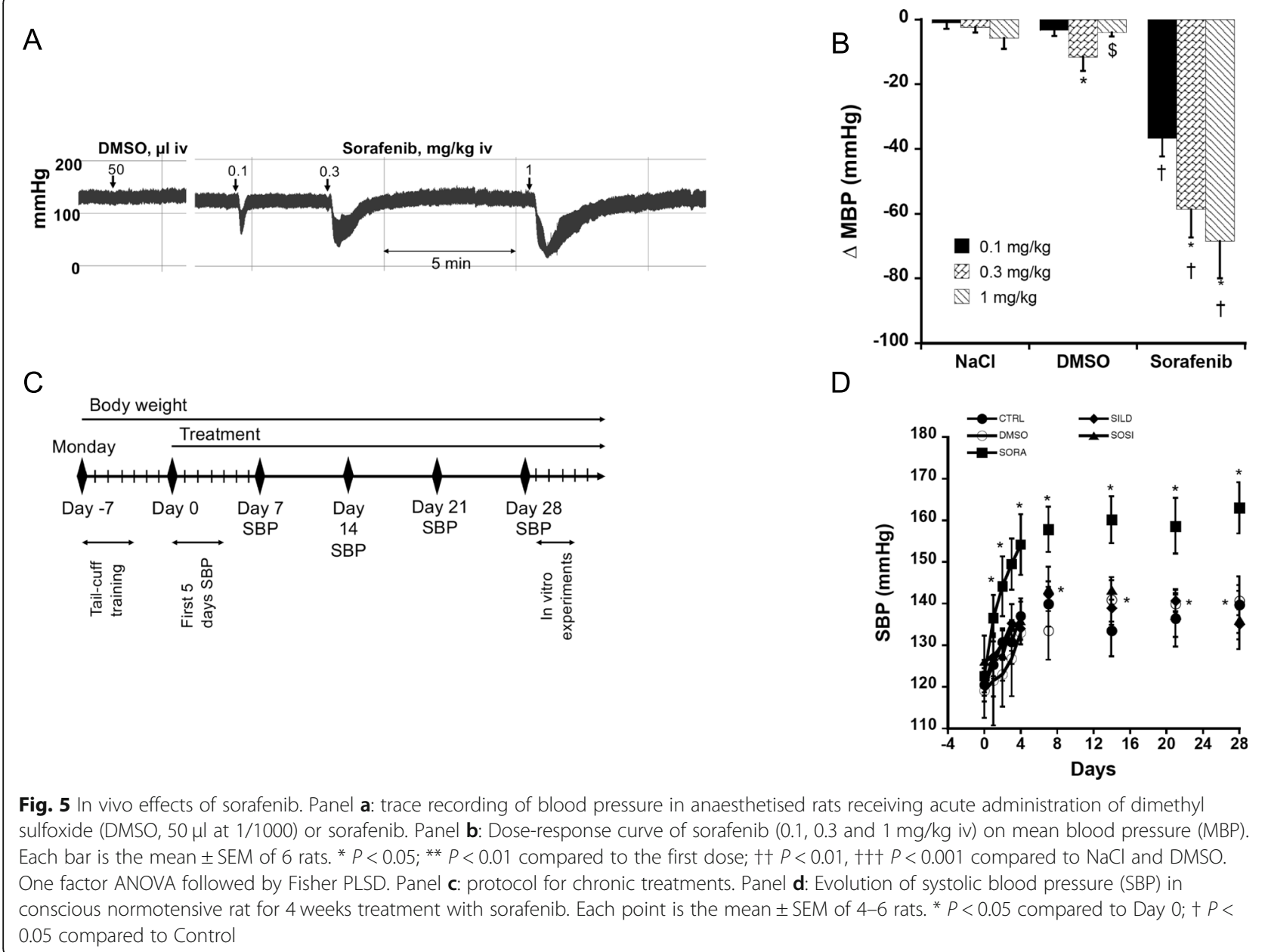

blood pressure was recorded by telemetry or tail-cuff. The changes in arterial blood pressure were dosedependent and appeared in the first week after starting the treatment $[18,21,23]$. In the present study, at the end of the treatment, SBP reached normotensive values of $140 \mathrm{mmHg}$ in CTRL, DMSO and SILD groups. Sorafenib induced hypertension with increased SBP to 160 $\mathrm{mmHg}$. The onset of sorafenib-induced increase in SBP was similar to that already reported. In vitro investigations showed that the vasorelaxation induced by sorafenib was almost abolished in aortic rings obtained from chronically sorafenib-treated rats. In this context, in conscious rats, chronic administration of sildenafil normalized values of systolic blood pressure from the very first days of sorafenib treatment and overall, throughout the protocol, sildenafil abolished the hypertensive effect of sorafenib and SBP values were similar to those of CTRL and DMSO groups. In our experimental conditions, sildenafil per se induced vasorelaxation as previously reported and ascribed to amplification of NO/cGMP pathways through inhibition of PDE-5 [28, 53]. This suggests that acting on cGMP pathway including NO signalling may represent a suitable strategy for the treatment of sorafenib-induced hypertension.

The present experiments report the effects of sorafenib on isolated large conductance artery, the rat aorta, and the pharmacological mechanisms implicated. In rat aorta precontracted by noradrenaline, sorafenib induced concentration-dependent vasorelaxation, the pharmacological mechanism of which appeared complex. The reduction of the effects of sorafenib after endothelium removal suggests that its vasodilatory effects are both endothelium dependent and endothelium independent. Many mechanisms are implicated in the endothelium dependent and independent vasorelaxation [47, 48]. Our results led us to conclude that sorafenib-induced vasorelaxation involves $\mathrm{NO}$, prostaglandins, cGMP and $\mathrm{Na} / \mathrm{K}-$ ATPase. However, since combined inhibition of different pathways did not completely suppress the effects of sorafenib, other mechanisms could not be excluded, as hydrogen peroxide or epoxyeicosatrienoic acid pathways, although their importance might be negligible. 


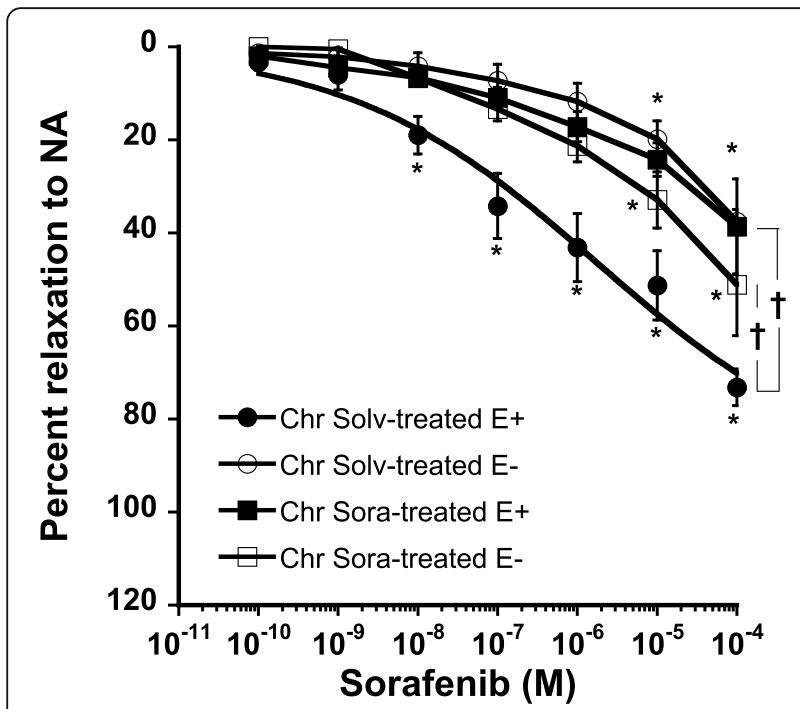

Fig. 6 Concentration response curves of sorafenib in endothelium intact $(E+)$ or denuded (E-) aortic ring of rats treated for 4 weeks with solvent (chr Solv) or sorafenib (chr Sora). Mean \pm SEM of 3-6 rats. ${ }^{*} P<0.01$ vs first concentration. $+P<0.05$ comparison of the different curves. Anova for repeated measures

Sorafenib-induced vasorelaxation in vitro appeared paradoxical in regard to the increase in blood pressure in vivo. However, direct activation of growth factor receptors as EGFR and PDGFR induced vasoconstriction of aorta from normotensive, spontaneously hypertensive or 1 kidney, 1 clip $(1 \mathrm{~K}, 1 \mathrm{C})$ hypertensive rats [54-57]. Thus, it seems not surprising that inhibition of these growth factor receptors by TKIs would induce vascular smooth muscle cell relaxation and vasodilatation as reported in rat pulmonary arteries [24] and aorta (the present results).

It should be acknowledged that the effects of sorafenib on resistance vessels were not assessed in the present study. These vessels are the most implicated in the control of peripheral resistance. However, it is likely that the vasodilatory effects observed in large conductance arteries could also be observed in these small arteries as in the present study, bolus intravenous administrations of sorafenib decreased arterial blood pressure. These results are also in agreement with previous reports showing that TKIs induce vasorelaxation in pulmonary and renal arteries [22, 24]. Finally, we did not directly assess endothelium removal with markers such as CD31. However, in all rings, we ensure the functional presence or absence when endothelium was removed using acetylcholine, a well-recognized approach.

Two other aspects need also to be discussed. First, the long-term use of sildenafil might have impact on penile erection. In our experiments, simple observation of the rats without any specific measurement did not reveal that chronic treatment with sildenafil induced penile erection. One could hypothesize that the doses used in the present study are lower than those required to induce penile erection. However, our study was not designed to allow such conclusion and specific investigations are needed to address this issue. It should be also acknowledged that the rats did not have tumors in the present study. Therefore, further experiments are needed to verify that sildenafil does not interact with the anticancer properties of sorafenib experimentally in a rat model of hepatocellular carcinoma [58] before stuying this strategy in patients.

\section{Conclusions}

The present results show that the multikinase inhibitor sorafenib induced in vitro vasorelaxation of large conductance artery, primary by activating soluble guanylate cyclase. Its chronic administration led to arterial blood hypertension that was counteracted by a PDE- 5 inhibitor, sildenafil. Our results suggest that targeting the cGMP pathway including NO signalling might be an interesting pharmacological strategy for the treatment of TKI-induced hypertension.

\section{Abbreviations \\ Ach: Acetylcholine; BP: Blood pressure; COX: Cyclo-oxygenase; \\ DMSO: Dimethyl sulfoxide; INDO: Indomethacin; NA: Noradrenaline; NO: Nitric oxide; ODQ: (1H-[1,2,4]oxadiazolo[4,3-a]quinoxalin-1-one); OUA: Ouabain; PDGF: Platelet Derived Growth Factor; $\mathrm{PGI}_{2}$ : Prostacyclin SBP: Systolic blood pressure; SILD: Sildenafil; SORA: Sorafenib; SOSI: Sorafenib + sildenafil; TKIs: Tyrosine kinase inhibitors; U73122: (1-[6-\{[17ß-3- methoxyestra-1,2,3(10)-trien-17-yl]amino\}hexyl]-1H-pyrrole-2,5-dione); VEGF: Vascular endothelial growth factor}

\section{Acknowledgements}

Not applicable.

\section{Authors' contributions}

HD designed and performed the experiments, analysed the data and write the manuscript. FD and CN performed part of the experiments. BG conceived the experiments, revised and submitted the manuscript. All authors read and approved the final manuscript.

\section{Funding}

Not applicable.

\section{Availability of data and materials Not applicable.}

Ethics approval and consent to participate

This study was approved by our local animal ethical committee [ComEth AFSSA-ENVA-UPEC approval \#12/09/17-3].

Consent for publication

Not applicable.

\section{Competing interests}

The authors declare that they have no competing interests.

Received: 4 May 2020 Accepted: 3 July 2020

Published online: 13 July 2020

\section{References}

1. Arora A, Scholar EM. Role of tyrosine kinase inhibitors in cancer therapy. J Pharmacol Exp Ther. 2005;315:971-9. 
2. McDermott U, Settleman J. Personalized cancer therapy with selective kinase inhibitors: an emerging paradigm in medical oncology. J Clin Oncol Off J Am Soc Clin Oncol. 2009;27:5650-9.

3. Takeuchi K, Ito F. Receptor tyrosine kinases and targeted cancer therapeutics. Biol Pharm Bull. 2011;34:1774-80.

4. Eckstein N, Röper L, Haas B, Potthast H, Hermes U, Unkrig C, et al. Clinical pharmacology of tyrosine kinase inhibitors becoming generic drugs: the regulatory perspective. J Exp Clin Cancer Res CR. 2014;33:15.

5. Robinson ES, Khankin EV, Karumanchi SA, Humphreys BD. Hypertension induced by vascular endothelial growth factor signaling pathway inhibition: mechanisms and potential use as a biomarker. Semin Nephrol. 2010;30:591-601.

6. Dirix L, Rutseart R. Arterial hypertension induced by vascular endothelial growth factor interfering agents: mechanisms and management. Belg J Med Oncol. 2010;4:159-67.

7. Escalante CP, Zalpour A. Vascular endothelial growth factor inhibitor-induced hypertension: basics for primary care providers. Cardiol Res Pract. 2011;2011:816897.

8. Funakoshi T, Latif A, Galsky MD. Risk of hypertension in cancer patients treated with sorafenib: an updated systematic review and meta-analysis. J Hum Hypertens. 2013;27:601-11

9. Agarwal M, Thareja N, Benjamin M, Akhondi A, Mitchell GD. Tyrosine kinase inhibitor-induced hypertension. Curr Oncol Rep. 2018;20:65

10. Rixe $\mathrm{O}$, Billemont $\mathrm{B}$, Izzedine $\mathrm{H}$. Hypertension as a predictive factor of Sunitinib activity. Ann Oncol. 2007;18:1117.

11. Jain RK, Duda DG, Willett CG, Sahani DV, Zhu AX, Loeffler JS, et al. Biomarkers of response and resistance to antiangiogenic therapy. Nat Rev Clin Oncol. 2009:6:327-38.

12. Veronese ML, Mosenkis A, Flaherty KT, Gallagher M, Stevenson JP, Townsend RR, et al. Mechanisms of hypertension associated with BAY 439006. J Clin Oncol Off J Am Soc Clin Oncol. 2006;24:1363-9.

13. Lankhorst S, Kappers MHW, van Esch JHM, Danser AHJ, van den Meiracker $\mathrm{AH}$. Hypertension during vascular endothelial growth factor inhibition: focus on nitric oxide, endothelin-1, and oxidative stress. Antioxid Redox Signal. 2014;20:135-45.

14. Alivon M, Giroux J, Briet M, Goldwasser F, Laurent S, Boutouyrie P. Large artery stiffness and hypertension after antiangiogenic drugs: influence on cancer progression. J Hypertens. 2015;33:1310-7.

15. Touyz RM, Herrmann SMS, Herrmann J. Vascular toxicities with VEGF inhibitor therapies-focus on hypertension and arterial thrombotic events. Am Soc Hypertens. 2018;12:409-25.

16. de Jesus-Gonzalez N, Robinson E, Moslehi J, Humphreys BD. Management of antiangiogenic therapy-induced hypertension. Hypertension. 2012;60:607-15.

17. Kruzliak P, Novák J, Novák M. Vascular endothelial growth factor inhibitor-induced hypertension: from pathophysiology to prevention and treatment based on long-acting nitric oxide donors. Am J Hypertens. 2014;27:3-13.

18. Kappers MHW, van Esch JHM, Sluiter W, Sleijfer S, Danser AHJ, van den Meiracker $\mathrm{AH}$. Hypertension induced by the tyrosine kinase inhibitor sunitinib is associated with increased circulating endothelin-1 levels. Hypertension. 2010;56:675-81.

19. Kappers MHW, Smedts FMM, Horn T, van Esch JHM, Sleijfer S, Leijten F, et al The vascular endothelial growth factor receptor inhibitor sunitinib causes a preeclampsia-like syndrome with activation of the endothelin system. Hypertension. 2011;58:295-302.

20. Kappers MHW, de Beer VJ, Zhou Z, Danser AHJ, Sleijfer S, Duncker DJ, et al. Sunitinib-induced systemic vasoconstriction in swine is endothelin mediated and does not involve nitric oxide or oxidative stress. Hypertension. 2012;59:151-7.

21. Nagasawa T, Hye Khan MA, Imig JD. Captopril attenuates hypertension and renal injury induced by the vascular endothelial growth factor inhibitor sorafenib. Clin Exp Pharmacol Physiol. 2012;39:454-61.

22. Grisk O, Koenen A, Meissner T, Donner A, Braun D, Steinbach A, et al. Rho kinase inhibition mitigates sunitinib-induced rise in arterial pressure and renal vascular resistance but not increased renal sodium reabsorption. J Hypertens. 2014;32:2199-210 discussion 2110.

23. Isobe T, Komatsu R, Honda M, Kuramoto S, Shindoh H, Tabo M. Estimating the clinical risk of hypertension from VEGF signal inhibitors by a non-clinical approach using telemetered rats. J Toxicol Sci. 2014;39:237-42.

24. Abe K, Toba M, Alzoubi A, Koubsky K, Ito M, Ota H, et al. Tyrosine kinase inhibitors are potent acute pulmonary vasodilators in rats. Am J Respir Cell Mol Biol. 2011:45:804-8.

25. Wilhelm SM, Carter C, Tang L, Wilkie D, McNabola A, Rong H, et al. BAY 439006 exhibits broad spectrum oral antitumor activity and targets the RAF/
MEK/ERK pathway and receptor tyrosine kinases involved in tumor progression and angiogenesis. Cancer Res. 2004;64:7099-109.

26. Morabito A, De Maio E, Di Maio M, Normanno N, Perrone F. Tyrosine kinase inhibitors of vascular endothelial growth factor receptors in clinical trials: current status and future directions. Oncologist. 2006;11:753-64.

27. Terrett NK, Bell AS, Brown D, Ellis P. Sildenafil (VIAGRA (TM)), a potent and selective inhibitor of type 5 cGMP phosphodiesterase with utility for the treatment of male erectile dysfunction. Bioorg Med Chem Lett. 1996;6: 1819-24.

28. Teixeira CE, Priviero FBM, Webb RC. Differential effects of the phosphodiesterase type 5 inhibitors sildenafil, vardenafil, and tadalafil in rat aorta. J Pharmacol Exp Ther. 2006;316:654-61.

29. Savai R, Pullamsetti SS, Banat G-A, Weissmann N, Ghofrani HA, Grimminger $F$, et al. Targeting cancer with phosphodiesterase inhibitors. Expert Opin Investig Drugs. 2010;19:117-31.

30. Lin C-S, Lau A, Tu R, Lue TF. Expression of three isoforms of cGMP-binding cGMP-specific Phosphodiesterase (PDE5) in human penile Cavernosum. Biochem Biophys Res Commun. 2000;268:628-35.

31. Guazzi M. Clinical use of Phosphodiesterase-5 inhibitors in chronic heart failure. Circ Heart Fail. 2008;1:272-80.

32. Trochu JN, Leblais $V$, Rautureau Y, Bévérelli F, Le Marec $H$, Berdeaux A, et al. Beta 3-adrenoceptor stimulation induces vasorelaxation mediated essentially by endothelium-derived nitric oxide in rat thoracic aorta. $\mathrm{Br} J$ Pharmacol. 1999;128:69-76.

33. Iturrioz X, Alvear-Perez R, De Mota N, Franchet C, Guillier F, Leroux V, et al. Identification and pharmacological properties of E339-3D6, the first nonpeptidic apelin receptor agonist. FASEB J. 2010;24:1506-17.

34. Dabiré H, Barthélémy I, Blanchard-Gutton N, Sambin L, Sampedrano CC, Gouni V, et al. Vascular endothelial dysfunction in Duchenne muscular dystrophy is restored by bradykinin through upregulation of eNOS and nNOS. Basic Res Cardiol. 2012;107:1-9.

35. Bleasdale JE, Thakur NR, Gremban RS, Bundy GL, Fitzpatrick FA, Smith RJ et al. Selective inhibition of receptor-coupled phospholipase C-dependent processes in human platelets and polymorphonuclear neutrophils. J Pharmacol Exp Ther. 1990;255:756-68.

36. Ong $W-Y$, Farooqui $T$, Kokotos G, Farooqui AA. Synthetic and natura inhibitors of phospholipases a (2): their importance for understanding and treatment of neurological disorders. ACS Chem Neurosci. 2015;6: 814-31.

37. Rees DD, Palmer RM, Schulz R, Hodson HF, Moncada S. Characterization of three inhibitors of endothelial nitric oxide synthase in vitro and in vivo. $\mathrm{Br} J$ Pharmacol. 1990;101:746-52

38. Hawkey CJ. COX-1 and COX-2 inhibitors. Best Pract Res Clin Gastroenterol. 2001;15:801-20.

39. Patrignani $P$, Patrono C. Cyclooxygenase inhibitors: from pharmacology to clinical read-outs. Biochim Biophys Acta. 1851;2015:422-32.

40. Griffoni C, Spisni E, Strillacci A, Toni M, Bachschmid MM, Tomasi V. Selective inhibition of prostacyclin synthase activity by rofecoxib. J Cell Mol Med. 2007;11:327-38.

41. Moro MA, Russel RJ, Cellek S, Lizasoain I, Su Y, Darley-Usmar VM, et al. cGMP mediates the vascular and platelet actions of nitric oxide: confirmation using an inhibitor of the soluble guanylyl cyclase. Proc Natl Acad Sci. 1996; 93:1480-5.

42. Olson LJ, Knych ET, Herzig TC, Drewett JG. Selective guanylyl cyclase inhibitor reverses nitric oxide-induced vasorelaxation. Hypertension. 1997;29: 254-61.

43. Zhao Y, Brandish PE, DiValentin M, Schelvis JPM, Babcock GT, Marletta MA Inhibition of soluble Guanylate Cyclase by ODQ†. Biochemistry. 2000;39: 10848-54.

44. Leung $H S$, Leung FP, Yao $X, K o W H$, Chen Z-Y, Vanhoutte PM, et al. Endothelial mediators of the acetylcholine-induced relaxation of the rat femoral artery. Vasc Pharmacol. 2006:44:299-308.

45. Cosson E, Herisse M, Laude D, Thomas F, Valensi PE, Attali JR, et al. Aortic stiffness and pulse pressure amplification in Wistar-Kyoto and spontaneously hypertensive rats. Am J Physiol Heart Circ Physiol. 2007;292:H2506-12.

46. Krege JH, Hodgin JB, Hagaman JR, Smithies O. A noninvasive computerized tail-cuff system for measuring blood pressure in mice. Hypertension. 1995; 25:1111-5.

47. Shimokawa H, Matoba T. Hydrogen peroxide as an endothelium-derived hyperpolarizing factor. Pharmacol Res Off J Ital Pharmacol Soc. 2004:49:543-9. 48. Félétou M, Vanhoutte PM. EDHF: an update. Clin Sci. 2009;117:139-55. 
49. Humphreys BD, Atkins MB. Rapid development of hypertension by sorafenib: toxicity or target? Clin Cancer Res. 2009;15:5947-9.

50. Maitland ML, Kasza KE, Karrison T, Moshier K, Sit L, Black HR, et al. Ambulatory monitoring detects sorafenib-induced blood pressure elevations on the first day of treatment. Clin Cancer Res. 2009;15:6250-7.

51. Akutsu N, Sasaki S, Takagi H, Motoya M, Shitani M, lgarashi M, et al. Development of hypertension within 2 weeks of initiation of sorafenib for advanced hepatocellular carcinoma is a predictor of efficacy. Int I Clin Oncol. 2015;20:105-10.

52. Li Y, Gao Z-H, Qu X-J. The adverse effects of sorafenib in patients with advanced cancers. Basic Clin Pharmacol Toxicol. 2015;116:216-21.

53. Sharabi FM, Daabees TT, El-Metwally MA, Senbel AM. Effect of sildenafil on the isolated rat aortic rings. Fundam Clin Pharmacol. 2005;19:449-56.

54. Berk BC, Alexander RW. Vasoactive effects of growth factors. Biochem Pharmacol. 1989;38:219-25.

55. Sauro MD, Thomas B. Tyrphostin attenuates platelet-derived growth factorinduced contraction in aortic smooth muscle through inhibition of protein tyrosine kinase(s). J Pharmacol Exp Ther. 1993;267:1119-25.

56. Florian JA, Watts SW. Epidermal growth factor: a potent vasoconstrictor in experimental hypertension. Am J Phys. 1999;276:H976-83.

57. Fernandez-Patron C. Therapeutic potential of the epidermal growth factor receptor transactivation in hypertension: a convergent signaling pathway of vascular tone, oxidative stress, and hypertrophic growth downstream of vasoactive G-protein-coupled receptors? Can J Physiol Pharmacol. 2007;85 97-104.

58. Santos NP, Colaço AA, Oliveira PA. Animal models as a tool in hepatocellular carcinoma research: a review. Tumour Biol. 2017;39: 1010428317695923

\section{Publisher's Note}

Springer Nature remains neutral with regard to jurisdictional claims in published maps and institutional affiliations.

Ready to submit your research? Choose BMC and benefit from:

- fast, convenient online submission

- thorough peer review by experienced researchers in your field

- rapid publication on acceptance

- support for research data, including large and complex data types

- gold Open Access which fosters wider collaboration and increased citations

- maximum visibility for your research: over $100 \mathrm{M}$ website views per year

At $\mathrm{BMC}$, research is always in progress.

Learn more biomedcentral.com/submissions 